\title{
Impacts of the internet on perceptions of governance at the community level: the case of Jiangqiao Township in Shanghai, China
}

\author{
Yili Yao and Xianghong Zhou \\ School of Economics and Management, Tongji University, Shanghai, China
}

\begin{abstract}
Purpose - The rate of urbanisation in China has accelerated community heterogeneity, and yet it has also led to challenges and problems in community governance. This trend has been accompanied by the rapid expansion of information and communication technology (ICT) and online activities. Based on the example of Jiangqiao Township in Shanghai, this paper aims to probe the link between online participation using the internet and its impacts on social capital formation and community development.

Design/methodology/approach - A literature review was conducted, and a case study method based on quantitative data was applied to test the theoretical framework in the interactions of users' online participation and perceptions of community governance.

Findings - Participation in an online community through the internet was found to foster new social capital. Distributed social capital had a positive impact on perceptions of governance at the community level, which was due to the resulting network density and social trust of the locality.

Originality/value - This study offers an expanded perspective on the impact of the internet on the behaviour of netizens in China in the context of community governance in new settlements and townships. During the COVID-19 pandemic, it is interesting to investigate how the use of mass communication channels, such as the internet and other digital platforms, affects social behaviour and generates new social norms. This study offers quantitative evidence from China to support the theory of Putnam (1993; 1995a). It thus extends beyond the field of sociology to the fields of public administration and urban development.
\end{abstract}

Keywords Community governance, Social capital, Internet, Social integration, Migration

Paper type Research paper

\section{Introduction}

In the past two decades, China's rapid urbanisation has led to many new urban or peri-urban communities and settlements. These emerging communities have experienced rapid population influxes, and they are faced with increasing heterogeneity and fragmentation. Many new residents found themselves living in an unfamiliar urban environment, and they have increasingly experienced social anomy. These trends have become critical issues that have affected community cohesion and its governance. Both local government and residents have experienced dissatisfaction with this situation.

In the past two decades, the internet has become widely available in China. According to the $39^{\text {th }}$ Statistical Report on the Development of China's Internet Network, internet penetration had already reached 53.2 percent by December 2016, and Shanghai had the

(C) Yili Yao and Xianghong Zhou. Published in Public Administration and Policy. Published by Emerald Publishing Limited. This article is published under the Creative Commons Attribution (CC BY 4.0) license. Anyone may reproduce, distribute, translate and create derivative works of this article (for both commercial and non-commercial purposes), subject to full attribution to the original publication and authors. The full terms of this license may be seen at http://creativecommons.org/licences/by/4.0/ legalcode

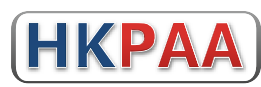


highest penetration rate of 74.1 percent (Cyberspace Administration of China, 2017).

Currently, most Chinese residents in urban communities have established new ways of interpersonal communication with their neighbours through using the internet and mobile devices. The internet has created new opportunities for Chinese communities from ecommerce to online learning, and from information exchange to social contacts. Could these online channels also offer new pathways to community development, impact local governance and ease communication and information exchange?

Combining a literature review and a case study approach, this paper uses social capital theory and the improved Baron and Kenny (1986) mediation analysis model to explore the mediating role of social capital in internet participation and community governance. Recommendations are provided at the end of this paper to map the findings of other localities that facing similar challenges. The recommendations include replicating this study in other new towns in similar or divergent local socio-economic contexts to identify alternative policies to increase the effectiveness of community development and governance.

\section{Literature review}

Concept and composition of social capital

The concept of social capital originated in the 1970s. Although there has been a variety of definitions, the core of social capital consists of networks, norms and trust. Coleman (1990) argued that social capital consists of three main components: social network, social trust and social participation. Putnam (1995a) proposed that social capital refers to features of social organisation that facilitate coordination and cooperation for mutual benefit. Social capital consists of three components: moral obligations and norms, social values (especially trust) and social networks (especially voluntary associations). Putnam's central thesis (1993) was that if a region has a well-functioning economic system and a high level of political integration, they are the result of the successful accumulation of social capital. He highlighted that norms of reciprocity and networks of civic engagement could promote social trust and that both were highly productive forms of social capital that would enable normative civic communities to solve their problems through collective action and the better promotion of economic prosperity and democratic governance (Yiu et al., 2020).

In the modern world, trust is essential for people when they leave familiar surroundings and move to an urban environment that is dominated by contingency, complexity and risk (Luhmann, 1988). Coleman (1988) believed that in the process of cooperation, people will have two different unintended consequences: either trust will be generated at a higher (macro) level, so that individuals will experience integration value; or lack of trust will lead to estrangement.

Trust is evidently the key currency in social capital. Stable network memberships and repeated community participation promote and strengthen social trust on both micro and macro levels. In measuring community or social trust, the following indicators are used: feeling of comfort or "safety" in sharing thoughts and feelings; discussing mistakes and problems; and being able to count on the "intention" of helpers to help (Amabile et al., 2014).

Community participation is used to measure reciprocity through social behaviour or engagement in collective actions. In this paper, two indicators of community participation are used as follows: (a) sustained social networks, such as maintaining and increasing the number of ongoing relationships, and (b) members' participation in collective actions, such as volunteering or contributing to efforts to resolve public concerns and/or participating in public debates on these public concerns.

The network is the carrier of social capital. Nahapiet and Ghoshal (1998) defined a network as the pattern of interconnections between individuals, which consists of contact, configuration and organisation. Based on the above definition, in measuring the network 
and its effects, this paper focuses on the network size, closeness and mode of connection to the internet utilised by individual residents surveyed in Jiangqiao Township.

\section{Internet as a source of social capital formation}

Nahapiet and Ghoshal (1998) suggested that social capital would be generated and maintained through continuous communication. Internet-based communities and social connectivity can be regarded as the largest and most extensive social network worldwide (Wellman et al., 2001). Using computers and mobile devices, people develop online social networks that exceed physical borders and share common interests and objectives. Whitty (2002) supported the idea that the internet provides a new opportunity for people to establish intimate relationships. Although there are significant challenges in establishing truly intimate relationships, she argued that if sufficient time was given, people could establish close interpersonal relationships through the internet. Other scholars (McKenna et al., 2002) found that surfing the internet did not mean avoiding real life and real relationships. Instead, they found that individuals used the internet not only to maintain existing relationships, but also to develop new intimate and meaningful relationships that were faster, stronger, deeper, and longer in a relatively threat-free environment.

In previous studies, some researchers revealed that the internet caused a decline in social capital, which was due to the time replacement effect. Their main augment was that the internet had reduced the amount of time spent in interactive communication and social participation, which had hindered the formation of social capital. Putnam (2000) pointed out that the development of modern technologies, such as television and the internet, had made people willing to stay at home rather than participate in social activities, which had led to a gradual decline in American social capital. In a similar study, Kraut et al. (1998) found that during the first one to two years of using the internet, both the social participation and the level of mental health of the interviewees decreased.

In contrast, other researchers found evidence that the internet had brought about an increase in social capital. Lin (1999) pointed out that the internet had created new social networks and social relations, which means social capital had not fallen but risen at the individual level. Interestingly, from 1998 to 1999, Kraut et al. (1998), who continued to research internet use, evidenced that the negative effects of the internet shown in previous studies had disappeared. On the contrary, the more internet is used, the higher the levels of social participation and mental health prevail.

These research findings indicate that the effects of the internet on social capital formation are complex and multifaceted. The relationship between internet use and social capital is less causal and a more gradual interactive process. With evolution over time, people's original social networks and implied social capital might be broken, and new social networks and social capital may be gradually cultivated.

\section{Community governance and its measures}

Bevir (2012) pointed out that governance included all governance processes regardless of whether they were conducted by governments, markets or networks; through a family, tribe, formal or informal organisation or territory; or through laws, regulations, power or language. The difference between governance and government management is that the former pays less attention to state and government activities, and more attention to social activities.

Putnam (1995b) explored the intrinsic link between social capital and community governance, and pointed out that levels of social capital determined the performance of community governance. Therefore, in assessing the effectiveness of governance, two outcome indicators are utilised: first, the improvement of a community's living standard; second, the level of social cohesion of a community as determinants.

\section{The case of Jiangqiao \\ Township in Shanghai}


PAP

24,2

168

In new public management (NPM), the public are considered as "customers", and the principle of "customer first" is applied to performance management in the public sector, which plays a positive role in improving the quality of public services. Correspondingly, performance evaluation adopts indicators that are subjective measures of public perception which directly reflect the public's evaluation of the performance of government services. At the community level, "customer satisfaction" is also a yardstick used to measure the fulfilment of community needs. The most intuitive reflection in this regard is the residents' subjective recognition of the achievements attained by the local government and its affiliates in implementing social governance policies in the community. This has been the basic principle of NPM since its launch in the late 1980s in the Western world and in China at the end of the 1990s (Xu, 2001).

Nevertheless, in assessing community governance based on subjective indicators, the question of reliability or relevance inevitably arises. At present, scholars are affirmative regarding the effectiveness of subjective evaluation and the use of subjective indicators, provided that such measures pay close attention to the selection of appropriate evaluation dimensions, the reliability of measurements, and appropriate evaluation strategies to safeguard the reliability of the findings.

\section{The mediating role of social capital between the internet and community governance}

This mediation effect will be reviewed as follows.

\section{The impact of the internet on social capital}

1. Amplification of benefits - Internet use can effectively improve network externalities. The benefits of internet use by individuals are proportional to the total number of internet users. In offline life, transaction costs in developing new relationships tend to increase due to limitations of time and energy. The transaction costs, on the other hand, of establishing and maintaining social networks could be greatly reduced because of network externalities.

2. Impact on trust - Modern information technology is an enabler in generating, recording and spreading the reputation of online personae. The transaction costs of a network reputation are far lower than those of real life. A network reputation can be comprehensive, transparent and fair, especially when the members of the social circle also interact with each other offline. This feature of the internet could solve the problem of trust in network communication if effective internet governance mechanisms existed.

3. Impact on social participation - The internet enables a stable exchange of repeated information. When a virtual community and a real community overlap and develop, people's desire for acceptance and belongingness by the group tends to grow, according to Maslow's needs hierarchy (1943). At this moment, it is possible to witness that private norms and rules emerge within a specific virtual community to consolidate the connectedness of its members, thus moving both private goods and public goods to members living in that community from online to offline.

\section{Impact of internet connectivity on community governance}

1. Enabling effect - The internet can effectively increase network density and continuously improve the network landscape to form lasting and functional community networks. These interconnected networks could increase the frequency of transactions regarding community governance. Optimising community networks 
and attracting the participation of multiple stakeholders in the community could increase the transparency of community governance, solve the problem of information asymmetry, and reduce transaction costs in the process of community governance.

\section{Impact of social capital on community governance}

1. Trust as an enabling factor - Trust enables multiple stakeholders in the community to predict the behaviour of other parties, thus making actors feel secure in sharing resources and communicating with each other based on mutual trust. Such predictability also alleviates the problems of benefit sharing and risk in community governance, and it effectively avoids opportunism and "free ride" behaviour.

2. Impact of social capital on community participation in community governance - The reciprocity norm consists of an effective commitment between multiple stakeholders, which can also encourage their participation in community public affairs, thus reducing the transaction costs of community governance. Moreover, community participation must be based on voluntary and equitable cooperation with the coordination and consent of diverse stakeholders in the community, leading to implicit and endogenous community norms. However, such norms tend to be unstable. This instability promotes the active innovation of community governance.

\section{Research methodology and hypotheses}

A multi-stage random sampling method was used to collect users' data on the internet and internet usage, social networking activities, and customers' feedback concerning perceptions of community services and their willingness to engage in local affairs. These data were analysed to identify the mediating effects of social capital. The following conceptualisation was developed to examine the cause-and-effect relationship between the variables (Figure 1).

The following hypotheses were formulated:

H1. The use of the internet and the internet increase the social capital of residents in their communities.

H2. Increasing the social capital of community residents has a positive effect on community governance.

H3. The use of the internet and the internet have positive effects on community governance, which is achieved through mediation by social capital.

The data analysis was conducted based on the mediation effect model developed by Wen and Ye (2014). This model is used to examine the process and mechanisms by which the independent variables influence the (non-observable) mediator variable, which then influences the dependent variable. Compared with similar research that analysed the

Independent variables

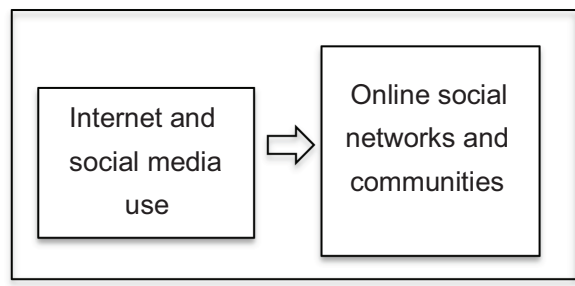

Intermediary variable Dependent variable

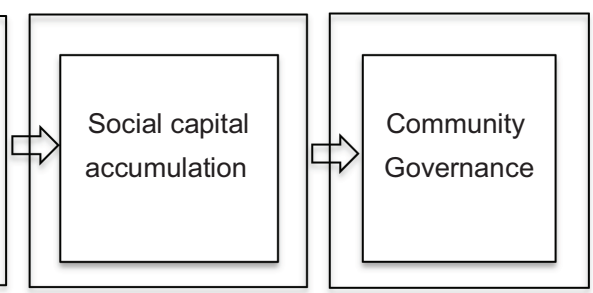

The case of Jiangqiao Township in Shanghai

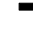


influence of the independent variable on the dependent variable, mediation analysis can obtain in-depth results. The results of the mediation analysis and the related regression equations are presented in the case study of Jiangqiao Township.

\section{Sample selection}

Jiangqiao Township is a typical example of urban development. Therefore, it was selected as the case study for this research. Jiangqiao Township is also a natural laboratory for policy exploration because its features are similar to those of many peri-urban townships located near major economic centres, which must respond creatively to the spill-over effects of large metropolitan areas.

This study was conducted in this complex socio-economic setting to determine the impact of internet use on individuals' social networks and the formation of social capital, resulting in their civic behaviour. It was hypothesised that individuals' participation in online communities affected their perceptions of and satisfaction with community governance at the local administrative level of a township.

\section{Case study of Jiangqiao Township Geodemographic profile of Jiangqiao Township}

Located in the northwest of Shanghai, Jiangqiao Township consists of 39 urban communities in an area of 42.47 square kilometres. By the end of 2016, Jiangqiao Township had a permanent population of $288,000,68.8$ percent of which lived within the township's parameters. The rest of the population lived in rural areas surrounding the township.

\section{Internet penetration in Jiangqiao Township}

In Jiangqiao Township, the rate of internet adoption was found to be similar to that in Shanghai. At the end of 2016, the percentage of broadband subscribers is around 21 percent; the monthly charge per mobile phone use is around 84 Renminbi; and the monthly mobile traffic per person is around $862 \mathrm{M}$ in both places.

\section{Social issues and community interactions}

Rapid urbanisation and migration have presented multiple challenges, such as stress on physical infrastructure, housing, social belonging, neighbourhood relations and social dynamics. Jiangqiao Township is no exception. The following social phenomena were observed:

(a) The rapid development of emerging settlements and large influx of "outside" populations

In 2001, there were only six communities in the urban centre of Jiangqiao Township. By the end of 2016, they had increased to 39, representing a six-fold growth, in which each community had 500-1,000 residents. Therefore, in the past 15 years, the urban population of Jiangqiao Township increased from 20,000 to 198,000 at an average annual growth rate of 16.5 percent.

(b) Increased heterogeneity or population mix in local communities

Among the permanent residents of the urban communities, the indigenous resident population was only 16.7 percent, who spoke the local dialect of Shanghai and shared common culinary customs and diet. The remaining 83.3 percent comprised the recent 
incoming population, which could be divided into two groups: those from other provinces and cities, accounted for 63.6 percent; the population from central Shanghai urban areas, accounted for the remaining 19.7 percent. A cultural divide existed between the indigenous, essentially rural population, and the newly immigrated cosmopolitan population mainly from Shanghai.

(c) Social trust in neighbours and psychology of safety

According to the findings of the survey conducted in this study, 51.6 percent of Jiangqiao Township residents felt they trusted their neighbours, 33.2 percent thought that their neighbours could be trusted, and 13.9 percent considered their neighbours untrustworthy. Similarly, the findings showed that the residents expressed different senses of safety in their respective localities.

(d) Decline in social participation

In contrast to the mature communities of Shanghai, the residents of Jiangqiao Township showed little willingness to participate in community affairs and actions. The findings of the survey showed that 82.6 percent of the survey respondents did not participate in any volunteering activities during the first half of 2016. Those who participated in one or two voluntary activities accounted for only 12.5 percent of the total. Only 2.1 percent of the sample participated in more than five voluntary activities.

Within one year, 78.2 percent of all Jiangqiao Township residents surveyed did not engage in collective problem solving or conflict resolution within their communities. The number of people who participated in collective problem solving amounted to only 14.4 percent, while those who volunteered more than two times accounted for 7.4 percent of the total.

\section{Quantitative survey}

From September 13 to October 10, 2016, a questionnaire survey was conducted in Jiangqiao Township, Shanghai. The survey covered all 39 communities in the township. A multi-stage random sampling method was used in the survey. The unit of sampling used in each stage was disaggregated according to community-building-householdresident. A total of 6,460 households were surveyed, which accounted for 7 percent of the total number of households in Jiangqiao Township (92,286 households). The person who completed the questionnaire was the first person the researcher met upon entering the home. Finally, a total of 6,384 valid questionnaires were obtained for the statistical analysis.

\section{Sample description}

The sample features are described in Table 1.

\section{Statistical method}

In recent years, in the social sciences and other research areas, many empirical studies have used the mediation effect model for data analysis. The mediation effect model examines the process and mechanisms by which the independent variable influences the (non-observable) mediator variable, which then influences the dependent variable. Compared with similar research that analysed the influence of the independent variable on the dependent variable, mediation analysis can obtain in-depth results. This study adopts five-step method by Wen and Ye (2014) to help conduct both the modelling and the data analytics. The model consists of the following three regression equations: 


\begin{tabular}{|c|c|c|c|}
\hline & & $\begin{array}{l}\text { Proportion } \\
\quad(\%)\end{array}$ & $\begin{array}{l}\text { Number of } \\
\text { Samples }\end{array}$ \\
\hline \multirow[t]{2}{*}{ Gender } & Male & 47.9 & 3061 \\
\hline & Female & 52.1 & 3323 \\
\hline \multirow[t]{4}{*}{ Marriage } & With spouse & 83.0 & 5297 \\
\hline & Unmarried & 7.3 & 467 \\
\hline & Divorced & 6.7 & 428 \\
\hline & Widow & 3.0 & 192 \\
\hline \multirow[t]{3}{*}{ Age } & Under 39 years old & 22.5 & 1438 \\
\hline & 40-59 years old & 28.6 & 1825 \\
\hline & More than 60 years old & 48.9 & 3121 \\
\hline \multirow{4}{*}{$\begin{array}{l}\text { Number of family } \\
\text { members }\end{array}$} & Three & 32.6 & 2082 \\
\hline & Two & 31.9 & 2036 \\
\hline & More than four & 25.1 & 1603 \\
\hline & Live alone & 10.4 & 663 \\
\hline \multirow{5}{*}{ Housing area } & Less than $50 \mathrm{~m}^{2}$ of house rental & 3.4 & 216 \\
\hline & $51-100 \mathrm{~m}^{2}$ & 72.3 & 4617 \\
\hline & $101-150 \mathrm{~m}^{2}$ & 22.5 & 1436 \\
\hline & $151-200 \mathrm{~m}^{2}$ & 0.9 & 57 \\
\hline & $200 \mathrm{~m}^{2}$ or more & 0.9 & 58 \\
\hline \multirow[t]{5}{*}{ Education } & Primary school or lower & 15.3 & 979 \\
\hline & Middle school & 34.3 & 2189 \\
\hline & High school & 23.9 & 1526 \\
\hline & $\begin{array}{l}\text { Secondary vocational school/ technical } \\
\text { school/ college }\end{array}$ & 18.9 & 1204 \\
\hline & Bachelor's degree or higher & 7.6 & 486 \\
\hline \multirow{4}{*}{$\begin{array}{l}\text { Ever surfing the } \\
\text { internet } \\
\text { Ever use of WeChat/QQ }\end{array}$} & Yes & 81.5 & 5203 \\
\hline & No & 18.5 & 1181 \\
\hline & Yes & 83.8 & 5351 \\
\hline & No & 16.2 & 1033 \\
\hline
\end{tabular}

Table 1.

Description of the samples

\section{2}

$$
\begin{gathered}
\mathrm{Y}=\mathrm{cX}+e_{1} \\
\mathrm{M}=\mathrm{aX}+e_{2} \\
\mathrm{Y}=\mathrm{c}^{\prime} \mathrm{X}+\mathrm{bM}+e_{3}
\end{gathered}
$$

Based on the mediation effect model, the independent variable $\mathrm{X}$ was set to the internet usage level of the respondent, and the mediation variable $\mathrm{M}$ was the social capital of the respondent.

The core of community governance is the satisfaction of residents' expectations, and the most intuitive reflection is the subjective recognition of the residents' community. The dependent variable $\mathrm{Y}$ was set as the respondent's assessment of community governance. Variable $\mathrm{Y}$ was used to measure the effects of the internet and social capital on community governance. The hypothesis that social capital is formed through the social use of the internet and affects perceptions of governance at the local level was supported.

In the model, coefficient $\mathbf{c}$ was the total effect of the usage level of the internet by the respondents on the perception of governance performance of the community. Coefficient a was the effect of the usage level of the internet by the respondents on social capital. Coefficient $\mathbf{b}$ was the effect of social capital on the perception of governance performance of the community after controlling for the influence of internet usage level. Coefficient c' was the direct effect of internet usage level on perceptions of governance performance of the community after 
controlling for the influence of social capital. Coefficients e1 to e3 were regression residuals. The mediation effect was equal to the indirect effect, and thus equal to the coefficient product $\mathrm{ab}$, which had the following relationship with the total effect and the direct effect: $\mathrm{c}=\mathrm{c}^{\prime}+\mathrm{ab}$.

\section{Measurement of variables}

The independent variable X "respondent's internet usage level" consisted of three aspects: internet resource richness, internet use intensity and internet interpersonal strength (Table 2).

The control variables included three consecutive variables: age, years of residence, and per capita housing space, and four sub-variables: household registration, work experience, marriage, and education level.

The mediator variable $\mathrm{M}$ was the individual social capital of the respondents, which consisted of three elements: social network, social trust and social participation. This study used social network density, community trust and frequency of community participation as proxies to measure the social capital possessed by each respondent. The total score for social capital was the sum of the indicators shown in Table 3. Each indicator was selected through application factor analysis combined with dimensionality reduction techniques.

The dependent variable $\mathrm{Y}$ was set as the perceived governance performance of the community, representing the respondents' evaluations of the governance of the community where they resided. This variable consisted of two aspects: community cohesion and community life (Table 4).

\section{Reliability and validity}

SPSS was used for the factor analysis and the analysis of the reliability of the scale.

First, the Kaiser-Meyer-Olkin (KMO) test was performed to determine whether the scale was suitable for the factor analysis. In general, the larger the KMO value is, the more common factors there are between the variables, and the more suitable it is for factor analysis. If the KMO value is less than 0.5 , the factor analysis should not be conducted. In addition, if Bartlett's sphericity test value is significant, it indicates that there are common factors between relevant correlation matrices and that the social capital scale is suitable for the factor analysis. Regarding the total explained variance, after the extraction using principal components analysis (PCA), the total explained variance without rotation was obtained. Common factors with an eigenvalue greater than 1 were extracted. This study referred to the results in selecting the common factors (Table 5). The validity of the sample was verified.

In evaluating the reliability statistics, the standardised $\alpha$ coefficient of 14 items on the scale was 0.925 , and the reliability measures passed the internal consistency test.

\begin{tabular}{lll}
\hline Measurement index & Definition & Indicators \\
\hline $\begin{array}{l}\text { Internet resource } \\
\text { richness }\end{array}$ & $\begin{array}{l}\text { Measure the easiness of per capita } \\
\text { internet facilities and the availability of } \\
\text { internet information in community } \\
\text { households. } \\
\text { Measure the frequency of internet use } \\
\text { by community residents. }\end{array}$ & $\begin{array}{l}\text { Number of devices with internet access } \\
\text { (including smart phones, TV with on- } \\
\text { demand technology, computer/iPads } \\
\text { and other internet devices) } \\
\text { Internet browsing frequency } \\
\text { Last month network usage fees }\end{array}$ \\
$\begin{array}{l}\text { Strength of social } \\
\text { interactions on the } \\
\text { internet }\end{array}$ & $\begin{array}{l}\text { Measure the scope and frequency of } \\
\text { community residents' interaction with } \\
\text { others through the internet. }\end{array}$ & $\begin{array}{l}\text { Fonth } \\
\text { Frequency of using WeChat/QQ } \\
\text { Frequency of using Weibo/forum }\end{array}$ \\
\end{tabular}
internet community residents' interaction with
The case of Jiangqiao Township in Shanghai
Table 2. Internet application measurement 
PAP

24,2

\section{4}

\begin{tabular}{ll}
\hline Measurement index & Main content \\
\hline Network density & $\begin{array}{l}\text { Measuring the online communication } \\
\text { patterns of respondents with their social } \\
\text { relations and social network within their } \\
\text { residing community }\end{array}$
\end{tabular}

Psychology of trust within the community community
Measuring the degree of mutual trust of respondents and residents of the same community

Measuring the degree of community participation by respondents
Indicators

Number of people available online for communication at any time

Times of talk in WeChat/QQ groups last week

Number of friends available online at any time

Frequency of talks in WeChat/QQ groups

Topic of talks initiated in WeChat/QQ groups by the respondent Number of members in WeChat/QQ groups constituted of local residents

Have asked for help from other residents through WeChat/QQ

Other residents have asked for help through WeChat/QQ

Extent of trust in online friends

Have sought comments and/or opinions from other residents through WeChat/ QQ

Other residents have sought comments and/or opinions through WeChat/QQ

Have mobilised residents through WeChat/QQ to come together to resolve common problems of the community Have responded to other residents' requests to join in the resolution of common problems through WeChat/QQ Am interested in the discussions within WeChat/QQ community groups
Table 3.

Measurement of social capital

\section{Findings}

1) Hypothesis 1 test results (Table 6):

H1. Social capital at the community level was increased by the internet and internet use by the residents.

H1a. The social network density of the community was increased by the internet and internet use by the residents.

$H 1 b$. The trust level of the community residents was increased by the internet and internet use by the residents.

H1c. Residents' participation in their community was increased by their internet use.

\section{2) Hypothesis 2 test results (Table 7)}

H2. Increased social capital of community residents had a positive effect on the perception of community governance.

H2a. Increased social network density of residents in the community had a positive effect on the perception of community governance.

H2b. Increased trust in the communities where residents lived had a positive effect on the perception of community governance. 


\begin{tabular}{ll}
\hline Measurement index & Main content \\
\hline $\begin{array}{l}\text { Assessment of } \\
\text { community cohesion }\end{array}$ & $\begin{array}{l}\text { Measures the respondents' perception } \\
\text { of the cohesiveness of their } \\
\text { community/neighbourhood }\end{array}$
\end{tabular}

Evaluation of community life

Measures the respondent's assessment of quality of life in the community.
Indicators

Does one like one's own community or neighbourhood?

Are residents willing to help each other? Are social relations among residents in the neighbourhood harmonious?

Does the respondent play an active role in maintaining the functioning of a community defined as economic activities, socialisation, social control, participation and mutual support?

Does the respondent feel an important member of community?

Are residents eager to be involved in local affairs?

Are residents enthusiastic about participating in WeChat $(\mathrm{QQ})$ groups or houseowners' forums?

In the eyes of residents, does the neighbourhood committee play an active role in maintaining community functions? In the eyes of residents, does the houseowners' committee play an active role in maintaining community functions? In the eyes of residents, does the property management company play an active role in maintaining community functions? Is the relationship between members of WeChat (QQ) groups or houseowners' forum harmonious? Is it possible to make friends through WeChat (QQ) groups or houseowners' forum?

Is there a sense of home in the community? Is the neighbourhood suitable for children?

\section{The case of Jiangqiao Township in Shanghai}

Is the neighbourhood suitable for older persons?

Are the grounds of the community safe? Are the issues discussed in community WeChat (QQ) groups or houseowner forums beneficial for raising children?

Are the issues discussed in community

WeChat (QQ) groups or houseowner forums beneficial for caring for older persons?

Table 4

Measurement of community governance performance

H2c. Increased community involvement of residents in their communities had a positive effect on the perception of community governance.

\section{3) Hypothesis 3 test results}

H3. The use of the internet had a positive effect on the perception of community governance (H3a) and was achieved through the mediating effects of social capital (H3b) (Table 8).

The results of the mediation effect test (Wen and Ye, 2014) showed that coefficient a and coefficient $\mathbf{b}$ were significant. Therefore, the hypothesised mediating effect of social capital 
PAP

24,2

was supported. However, coefficient c' was significant, indicating that the direct effect was also supported, and further testing was needed. The comparison of $a^{*} b$ and $c$ revealed that they were positive, indicating that the equation belonged to the partial mediating effect, and the ratio of the mediating effect to the total effect was $\mathrm{a}^{*} \mathrm{~b} / \mathrm{c}=56.87$ percent. Therefore, $\mathrm{H} 3 \mathrm{~b}$ was supported. The use of the internet had a positive effect on community governance, which was partially (56.87 percent) achieved through the intermediary effect of social capital.

\section{Discussion}

The findings of this study provide empirical evidence for the examination of the potential impacts of information and communication technology to ensure the growth of locality-based virtual communities. The focus of this study was on the impact of virtual communities through their social capital formation at individual and community levels on residents' satisfaction with local governance.

All hypotheses were supported. Using data analytics, the case study of Jiangqiao Township in Shanghai revealed that because of the increase in social capital, internet participation had a direct impact on the perceived performance of community governance. Promoting the active use of the internet and correctly combining virtual networks with community participation may lead to greater satisfaction regarding community governance among diverse and fragmented resident populations. The consequent social cohesion could strengthen local governance and improve the responsiveness of public services, thus creating a virtuous cycle. Social policies that support the greater participation and engagement of residents in digital life, especially the marginalised and vulnerable groups in the community, could provide access to social resources and complementary spaces for public discourse.

\section{Policy implications and recommendations}

In previous studies, researchers, governments, enterprises, and the media have all emphasised the convenience of service delivery through digitalisation and internet platforms. However, the endogenous social needs of the community in a digitalised world have seldom been discussed. Based on the findings of this research, the government should give more consideration to the intermediary effects of social capital, which the internet helps to foster and propagate. Through the connectivity of the internet, the potential for forming new interpersonal networks and promoting social participation and trust within the community is amplified, resulting in greater community integration in the process of rapid urbanisation throughout the country. In this context, the following policy priorities are proposed:

1. Expanding the digital skills and internet access for all residents

In addition to smartphones and computers, the government could actively promote the use of all kinds of internet devices and technologies, including the Internet of Things (IOT). It is also

Table 5.

Validity

\begin{tabular}{|c|c|c|c|c|}
\hline & & $\begin{array}{l}\text { Social } \\
\text { capital } \\
\text { scale }\end{array}$ & $\begin{array}{l}\text { Micro community } \\
\text { governance } \\
\text { performance scale }\end{array}$ & $\begin{array}{l}\text { Scale used to capture } \\
\text { the level of internet use } \\
\text { by respondents }\end{array}$ \\
\hline KMO & value & 0.655 & 0.928 & 0.827 \\
\hline Bartlett's & value & 1172.956 & 26677.004 & 7964.33 \\
\hline sphericity test & $\mathrm{p}$ & 0.00 & 0.00 & 0.00 \\
\hline Common factors & $\begin{array}{l}\text { Cumulative } \\
\text { variance } \\
\text { contribution rate }\end{array}$ & $69.718 \%$ & $67.629 \%$ & $51.692 \%$ \\
\hline
\end{tabular}




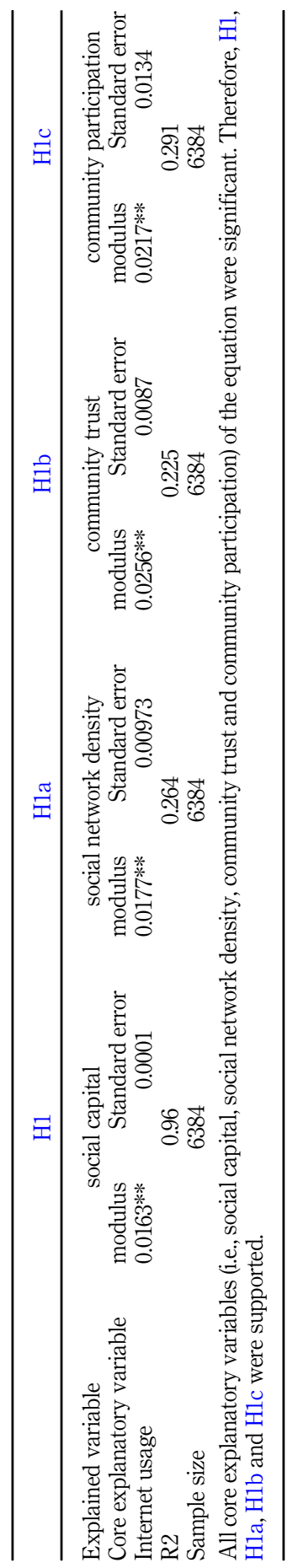

The case of Jiangqiao Township in

Shanghai

Table 6 H1 Hypothetical model test results 
PAP

24,2

178

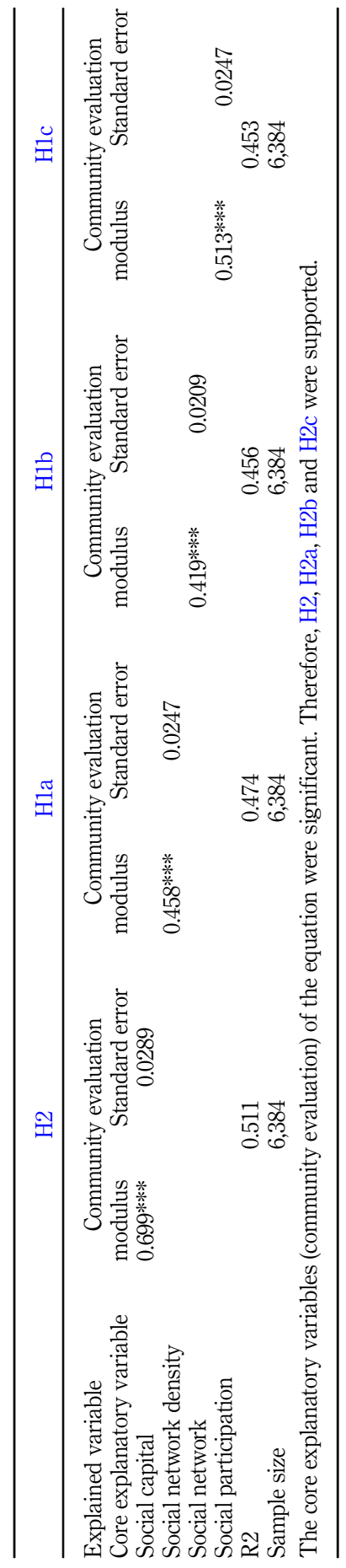

Table 7.

H2 Hypothetical model test results 


\begin{tabular}{|c|c|c|c|c|c|c|c|}
\hline & \multicolumn{2}{|c|}{ H3a } & \multicolumn{2}{|c|}{$\mathrm{H} 1$} & \multicolumn{2}{|c|}{$\mathrm{H} 3 \mathrm{~b}$} & The \\
\hline Explained & \multicolumn{2}{|c|}{ Community evaluation } & \multicolumn{2}{|c|}{ Community evaluation } & \multicolumn{2}{|c|}{ Community evaluation } & Township in \\
\hline $\begin{array}{l}\text { Core explanatory } \\
\text { variable }\end{array}$ & modulus & $\begin{array}{l}\text { Standard } \\
\text { error }\end{array}$ & modulus & $\begin{array}{l}\text { Standard } \\
\text { error }\end{array}$ & modulus & $\begin{array}{l}\text { Standard } \\
\text { error }\end{array}$ & Shang \\
\hline Internet usage & $\begin{array}{c}0.0027 * * * * \\
\text { (c) }\end{array}$ & 0.0002 & $\begin{array}{c}0.0168^{* * * *} \\
\text { (a) }\end{array}$ & 0.0001 & $\begin{array}{c}0.0009 * * * * \\
\left(c^{\prime}\right)\end{array}$ & 0.0001 & 179 \\
\hline \multicolumn{5}{|l|}{ Social capital } & $\begin{array}{c}0.0914^{* * * *} \\
\text { (b) }\end{array}$ & 0.0005 & \\
\hline \multicolumn{3}{|l|}{$\begin{array}{l}\text { R2 } \\
\text { Sample size }\end{array}$} & \multicolumn{2}{|c|}{$\begin{array}{c}0.98 \\
6,384\end{array}$} & \multicolumn{2}{|c|}{$\begin{array}{c}0.98 \\
6,384\end{array}$} & \\
\hline \multicolumn{7}{|c|}{$\begin{array}{l}\text { The core explanatory variables (community evaluation) of the above equations were significant, where } \\
\mathrm{a}=0.0168, \mathrm{~b}=0.0914, \mathrm{c}=0.0027, \text { and } \mathrm{c}^{\prime}=0.0009 . \\
\text { Coefficient } \mathbf{c} \text { was significant. Therefore, H3a was supported. }\end{array}$} & $\begin{array}{r}\text { Table } 8 \\
\text { Mediation effect mode } \\
\text { test results }\end{array}$ \\
\hline
\end{tabular}

important to provide technical support for people who do not have the skills to log on and surf the internet. In view of the imbalanced development of different parts of China, the government should increase the investment in ICT infrastructure and ensure the equalisation of public services to all localities and populations. Strategic guidance and system deployment should be strengthened to promote the rapid and inclusive distribution of internet infrastructure.

2. Cultivating the healthy development of the internet community and trust building

Social networks within the same community should be encouraged. WeChat (QQ) groups, houseowners' forums, and other internet communities could be guided and nurtured to enhance greater social interaction and the development of mutual trust over time. The government should pay attention to the views of internet leaders, such as WeChat users, regarding community development, prompt solutions to problems raised in the internet community, and the enhancement of residents' trust in internet communities. The government should encourage public organisations to actively participate in internet communities and be responsive to the public concerns expressed in online communities in a transparent manner.

3. Harvesting the social force of internet communities to further enhance community participation

Related to the effort in leveraging internet connectivity is to reinforce the norm of reciprocity. In the evolution of internet communities, the concurrent promotion of norms concerning formal or informal reciprocity could occur, which would enable social interactions on the internet to produce pro-social behaviour similar to socialisation in daily offline life. It could thus be said that while online social groups produce private goods for their members, online socialisation creates public goods for the benefit of the entire community.

\section{Research outlook}

Although the linear correlation between internet and internet participation and satisfaction in community governance was statistically proven in this study, other theoretical questions remain unanswered, and they require further scientific enquiry.

The first is about mediation variables. Step (2) (c' was significant) in the Wen and Ye (2014) mediation effect test confirmed that social capital mediates membership in virtual communities and reactions to community governance. Other mediating variables, however, were not excluded in dealing with the complex issue of social trust, citizen satisfaction with public services, power distribution and decision-making in public affairs. Each variable had a 
specific influence on the residents' perceptions. If these other intermediaries were also proven to mediate the independent and dependent variables, the question would be as follows: How do they then interact with social capital and other factors and the weight of their influence? These issues should be further studied. The identification of further mediating variables could deepen our insights into disruptive as well as ameliorating effects of ICT, as well as contribute to multifaceted policymaking.

Second, there are two sides to internet technology. This study showed the existence of a social compensation effect of the internet. However, does the time replacement effect exist at the same time? In other words, for most people, the social compensation effect is greater than the time replacement effect. However, for others, the internet deprives them of traditional interpersonal communication channels without establishing a healthy online communication channel, thus causing negative behavioural patterns, such as internet addiction, online gambling and so on. It is also possible that internet platforms offer the possibility of forming adversarial social groups and promoting intergroup competition and conflicts. Such adversarial interactions could lead to ethnic conflict and open expressions of racism.

Third, the scope and time of the present study should be increased. Jiangqiao Township of Shanghai represents those newly formed communities that are connected to large coastal cities in China. However, there are significant regional differences in the country. The development of urban and rural areas is not balanced, and the level of internet development (in both infrastructure and coverage) is also diverse. It is therefore necessary to conduct further case studies to capture ICT's role in social development in the broad landscape of emerging townships and communities around the country, especially in less advanced provinces. Because of the rapid development of internet connections, it is necessary to conduct regular tracking surveys at different times to reveal the interactional effects of internet use on experiences of community governance.

Finally, the application of data analytics in social science studies is a relatively novel approach. This study demonstrated the potential for using a bigger data set and mathematical computation to reveal underlying social patterns. This evidence-based approach could support tailored and nuanced public policymaking in meeting the challenges of social development.

\section{References}

Amabile, T.M., Fisher, C.M. and Pillemer, M. (2014), "IDEO's culture of helping”, Harvard Business Review, Vol. 92 Nos 1-2, pp. 54-61.

Baron, R.M. and Kenny, D.A. (1986), "The moderator-mediator variable distinction in social psychological research: conceptual, strategic, and statistical considerations", Journal of Personality and Social Psychology, Vol. 51 No. 6, pp. 1173-1182.

Bevir, M. (2012), Governance: A Very Short Introduction, OUP, Oxford.

Coleman, J. (1988), "Social capital in the creation of human capital", American Journal of Sociology, Vol. 94 No. 5, pp. 95-120.

Coleman, J. (1990), "Systems of trust and their dynamic properties", in Coleman, J. (Ed.), Foundations of Social Theory, Harvard University Press, Cambridge, pp. 175-196.

Cyberspace Administration of China (2017), "China statistical report on internet development", available at: http://www.cac.gov.cn/2017-01/22/c_1120352022.htm (in Chinese) (accessed 26 April 2021).

Kraut, R., Patterson, M., Lundmark, V., Kiesler, S., Mukophadhyay, T. and Scherlis, W. (1998), "Internet paradox: a social technology that reduces social involvement and psychological wellbeing?", American Psychologist, Vol. 53 No. 9, pp. 1017-1031.

Lin, N. (1999), "Building a network theory of social capital", Connections, Vol. 22 No. 1, pp. 28-51. 
Luhmann, N. (1988), "Familiarity, confidence, trust: problems and alternatives", in Gambetta, D. (Ed.), Trust: Making and Breaking Cooperative Relations, Basil Blackwell, Oxford, pp. 94-107.

Maslow, A.H. (1943), “A theory of human motivation”, Psychological Review, Vol. 50 No. 4, pp. 370-396.

McKenna, K.Y.A., Green, A.S. and Gleason, M.E.J. (2002), "Relationship formation on the internet: what's the big attraction?", Journal of Social Issues, Vol. 58 No. 1, pp. 9-31.

Nahapiet, J. and Ghoshal, S. (1998), "Social capital, intellectual capital, and the organizational advantage", The Academy of Management Review, Vol. 23 No. 2, pp. 242-266.

Putnam, R.D. (1993), Making Democracy Work: Civic Traditions in Modern Italy, Princeton University Press, Princeton.

Putnam, R.D. (1995a), "Bowling alone: America's declining social capital”, Journal of Democracy, Vol. 6 No. 1 , pp. $64-78$.

Putnam, R.D. (1995b), "Tuning in, tuning out: the strange disappearance of social capital in America", Political Science and Politics, Vol. 28 No. 4, pp. 664-683.

Putnam, R.D. (2000), Bowling Alone: The Collapse and Revival of American Community, Simon and Schuster, New York, N.Y.

Wellman, B., Haase, A.Q., Witte, J. and Hampton, K. (2001), "Does the internet increase, decrease, or supplement social capital?: Social networks, participation, and community commitment", American Behavioral Scientist, Vol. 45 No. 3, pp. 436-455.

Wen, Z. and Ye, B. (2014), "Analyses of mediating effects: the development of methods and models", Advances in Psychological Science, Vol. 22 No. 5, pp. 731-745.

Whitty, M.T. (2002), "Liar, liar! An examination of how open, supportive and honest people are in chat rooms", Computers in Human Behaviour, Vol. 18 No. 4, pp. 343-352.

$\mathrm{Xu}, \mathrm{S}$. (2001), "China's public administration reform: new approaches", Institute of Administrative Management, Proceedings of the Asia-Pacific Panel during the 2001 Annual Conference of International Institute of Administrative Sciences, Athens, December 5.

Yiu, L., Saner, R. and Bardy, R. (2020), "Collective action on public goods for sustainable development: ethics in action", Business Ethics and Leadership, Vol. 4 No. 4, pp. 14-27.

\begin{abstract}
About the authors
Yili Yao is a PhD student majoring in applied economics at Tongji University. He has been engaged in China's urban community service for years, and has done in-depth studies on the impact of urbanization and the internet. His research interests are social capital, community governance and the internet.

Xianghong Zhou, $\mathrm{PhD}$ in sociology from Nanjing University, is a professor and doctoral supervisor at School of Economics and Management, Tongji University. She is the Vice Chair of Shanghai Society of Public Administration Affairs, and the Director of Smart City and E-Governance Institute. Her projects were sponsored by National Natural Science Foundation of China, Social Science Research Council of United States, United Nations International Children's Emergency Fund, International Poverty Reduction Center in China, etc. She has published over 70 academic papers in professional core journals, with several policy recommendations adopted by the government. Her research interests are emerging technologies and urban development. Xianghong Zhou is the corresponding author and can be contacted at:xhz7@tongji.edu.cn
\end{abstract}

For instructions on how to order reprints of this article, please visit our website:

www.emeraldgrouppublishing.com/licensing/reprints.htm

Or contact us for further details: permissions@emeraldinsight.com 